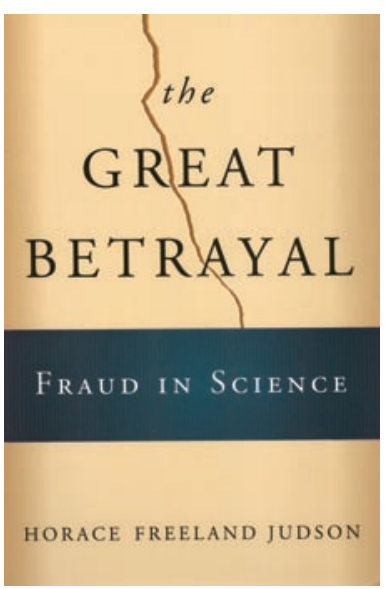

\section{The great betrayal}

Fraud in science

Horace Freeland Judson

Harcourt Inc. Orlando, Florida, USA. 2004.

480 pp. \$28.00. ISBN: 0-151-00877-9 (hardcover).

Reviewed by Alan Price

E-mail: aprice@osophs.dhhs.gov orace Judson's new historical commentary, The great betrayal: fraud in science, is a stimulating and thoughtful book for readers interested in science, publication ethics, and research misconduct. He writes with his typical flair, drawing on interviews with famous scientists. His premise is that scrutiny of the nature of fraud and other misconduct will reach to the pulse of what the sciences are and what scientists do. The book offers little, however, for readers whose principal interest is clinical research. Judson is a respected modern historian of science, perhaps best known for his history of molecular biology, The eighth day of creation: makers of the revolution in biology (S1). Most of the citations in this new book precede 1996, except for references to stories of misconduct among businessmen, historians, and journalists that have filled the press since 2000. In fact, the 35 "Recent Cases" are almost the same set of cases (late 1800s-late 1900s) previously described in Betrayers of the truth (S2) and False prophets (S3), neither of which is referenced in this new book. The newest cases cited in Judson's book involve major scandals in a German and an American laboratory, heavily covered in the recent science press. Nonetheless, Judson does profitably draw on the classical cases noted in these earlier books, drawing analogies with cases of scientific fraud during the past decade.

Also missing is a discussion of the findings of scientific misconduct in clinical cases made between 1992 and 2004 by the Office of Research Integrity (ORI), part of the United States Public Health Service (PHS) in the Department of Health and Human Services (HHS), which would have been of interest to JCI readers. About 40 of the 150 findings have involved clinical or related nonclinical research with human subjects (S4, S5). The only such case described by Judson is a clinical trial on the use of mastectomy versus lumpectomy to treat breast cancer, conducted at St. Luc's Hospital, Montreal, and coordinated by the University of Pittsburgh, in which the investigator falsified records to make more patients eligible for the study.

However, Judson includes a long, solid chapter on "The Baltimore Affair," dealing with the allegations of falsification of data on the part of a Massachusetts Institute of Technology scientist and the overturning of the ORI's 1994 finding against her in 1996 by the HHS appeals board. This case had been discussed in detail in 2 previous books, Science on trial: the whistle blower, the accused, and the Nobel laureate (S6), and The Baltimore case: a trial of politics, science, and character (S7), which also are not cited in Judson's new book. To his credit, Judson personally reviewed records and interviewed witnesses, describing both in much the same style as he used in The eighth day of creation (S1), which makes the new book a fascinating read.

Also striking is Judson's initial chapter, "A Culture of Fraud," describing public cases of fraud by businessmen, social scientists, clergy, and others. The conclusion is obvious: a few scientists are likely no better and no worse than the few members of the general population who are crooks and charlatans. His epilogue includes a plea to restore high standards to the conduct of scientific research.

Several interesting chapters, titled "The problems of peer review," "Authorship, ownership: problems of credit, plagiarism, and intellectual property," and "Laboratory to law: the problems of institutions when misconduct is charged" will be enlightening and challenging to readers who deal with such problems and try to teach students how to avoid them in the responsible conduct of research. Judson examines self-governance in science and whether officials, editors, and peers can deal effectively, without conflicts of interest, with deviations from appropriate standards in conducting, reporting, and reviewing research. He focuses as well on the important role of whistle-blowers or complainants in challenging some reports for reasons of integrity. Judson's book is accurate and timely, in that in 2000, the US Office of Science and Technology developed a uniform policy for dealing with allegations and investigations for all federal agencies. Each agency has since been publishing new policies or regulations; the revised HHS regulation should soon be finalized. In response, universities, research hospitals, and institutes are updating their policies and procedures, at least to address the federal government's new definition: "Research misconduct is defined as fabrication, falsification, or plagiarism in proposing, performing, or reviewing research, or in reporting research results ... [A] finding ... requires that: there be a significant departure from accepted practices of the relevant research community; and the misconduct be committed intentionally, or knowingly, or recklessly; and the allegation be proven by a preponderance of evidence." Judson has provided a nice history of the public debate over this definition through the 1990s and the creation of the ORI. His book accomplishes its goal, to describe and analyze the history of fraud in science and its impact on the scientific and public communities, and he examines what contributes to fraud. The book is recommended to readers interested in fundamental research ethics and their historical and political context in the new millennium.

This review represents the personal views of the author and not necessarily any position of the ORI, PHS, or HHS.

References are available online with this article; doi:10.1172/JCI200524343DS1. 